
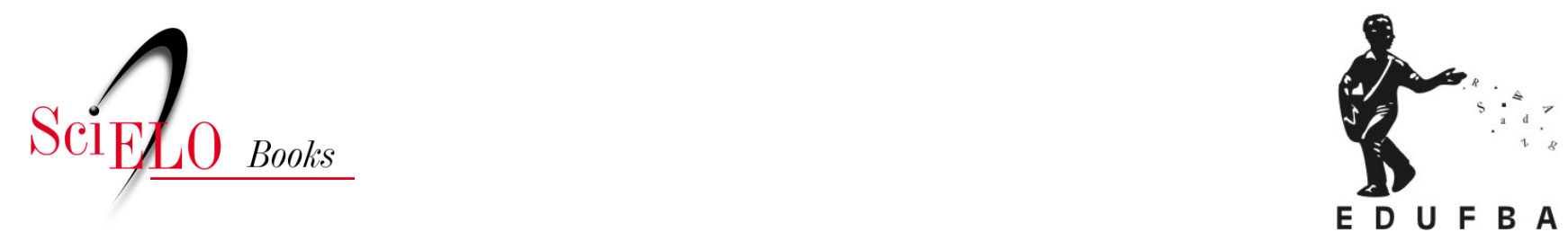

\title{
Capítulo 1 \\ A experiência de perdas gestacionais involuntárias: marcadores da transição desenvolvimental
}

\author{
Vívian Volkmer Pontes
}

\section{SciELO Books / SciELO Livros / SciELO Libros}

PONTES, V.V. A experiência de perdas gestacionais involuntárias: marcadores da transição desenvolvimental. In: Trajetórias interrompidas: perdas gestacionais, luto e reparação [online]. Salvador: EDUFBA, 2016, pp. 30-60. ISBN: 978-85-232-2009-9.

https://doi.org/10.7476/9788523220099.0003.

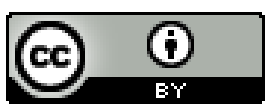

All the contents of this work, except where otherwise noted, is licensed under a Creative Commons Attribution 4.0 International license.

Todo o conteúdo deste trabalho, exceto quando houver ressalva, é publicado sob a licença Creative Commons Atribição 4.0. 
Capítulo 1

A experiência de perdas gestacionais involuntárias: marcadores da transição desenvolvimental 


\section{Aspectos subjetivos da experiência de perdas gestacionais involuntárias}

Na literatura vem crescendo o número de estudos que abordam os aspectos subjetivos da experiência de mulheres com perdas gestacionais involuntárias. No entanto, as pesquisas ainda privilegiam os aspectos biomédicos destas perdas, como se pode constatar considerando a grande parte dos estudos realizados no Brasil sobre esse tema. (Volkmer, 2009)

Entre os estudos nacionais que privilegiam os aspectos subjetivos relacionados à experiência de perdas gestacionais, pode-se destacar o trabalho de Santos, Rosenberg e Buralli (2004), qualitativo, que visou a (re) conhecer o significado de perda fetal (natimortos) para mulheres que vivenciaram tal experiência. De acordo com este estudo, a perda fetal pode representar uma crise em suas vidas, implicando na reconstrução das suas identidades. Já para Volkmer, Covas, Franco e Costa (2006), a partir da análise do perfil psicológico e social de mulheres com histórias de perdas gestacionais frequentes, em Salvador/BA, os abortos espontâneos recorrentes são vividos com sofrimento, tristeza e desânimo. Além disso, o significado de maternidade aparece fortemente idealizado e mobilizador de muitas expectativas, sendo o futuro condicionado ao nascimento de um filho.

Com relação aos aspectos emocionais observados em mulheres após a ocorrência de uma perda gestacional, Volkmer (2009), a partir de um estudo qualitativo realizado em Salvador/BA sobre os significados de maternidade para mulheres com história de perdas gestacionais recorrentes, relata que os sentimentos de culpa e de vulnerabilidade foram muito comuns entre as entrevistadas. O sentimento de culpa encontrou-se relacionado ao significado de causalidade atribuído às perdas, 
relacionado a alguma ação danosa empreendida pelas mulheres ou a algum problema de ordem física ou psíquica concernente a estas. Esse sentimento também apareceu de modo subjacente em algumas narrativas, como em situações em que as entrevistadas analisaram positivamente o fato dos parceiros não tê-las responsabilizado pelas perdas. Por sua vez, o sentimento de vulnerabilidade pessoal ao longo de cada nova tentativa de gravidez caracterizou o estado subjetivo de todas as entrevistadas. Ou seja, a gravidez, após a história de perdas gestacionais recorrentes, era percebida como um evento estressante, potencialmente ameaçador - visto que poderia levá-las a vivenciar no futuro determinados eventos avaliados como negativos, como complicações gestacionais, uma nova perda, conflitos familiares, entre outros -, e que suscitava emoções como o medo e a ansiedade.

A emergência do sentimento de culpa também foi identificada no estudo realizado em São Paulo/SP por Benute, Nomura, Pereira, Lucia e Zugaib (2009) com a finalidade de caracterizar a população que sofreu abortamento (provocado e espontâneo) e investigar a existência ou não de ansiedade e depressão através da aplicação de instrumento padronizado. Com relação à amostra de mulheres com abortamento espontâneo, o sentimento de culpa esteve relacionado à crença de que eram merecedoras de um castigo. Além disso, foi encontrada uma provável presença do transtorno de ansiedade, mas ausência de depressão.

A fim de lidar com essas incertezas futuras, Volkmer (2009) constatou que algumas mulheres tentaram se afastar da fonte de estresse, afirmando que não queriam mais engravidar. No entanto, essa decisão não se sustentava por muito tempo e elas voltavam a engravidar novamente. Isto aconteceu por várias razões: pela redução do sofrimento relacionado à última perda em função do passar do tempo, pelo uso inadequado de contraceptivos ou influenciadas pelo desejo do parceiro pela paternidade. Com a confirmação da gravidez, empreendiam outras estratégias de enfrentamento, como a tentativa de não se vincular afetivamente ao bebê em desenvolvimento - e assim, por exemplo, não comprar o enxoval, 
não dar um nome para o bebê e não compartilhar a notícia da gravidez com familiares e amigos.

Outro recurso de enfrentamento utilizado consistiu no esforço em manejar a situação causadora de estresse, como buscar atendimento médico especializado e fazer uso de algumas tecnologias médicas, submetendo-se a procedimentos cirúrgicos como a cerclagem e fazendo uso de medicamentos para "segurar o bebê" - mesmo quando envolviam sacrifícios pessoais, sofrimento físico e emocional.

$\mathrm{Na}$ literatura internacional, a descrição da experiência de nova gravidez após perda gestacional foi realizada por Coté-Arsenault e Freije (2004), por meio de um estudo fenomenológico nos Estados Unidos. As mulheres entrevistadas afirmaram que a gravidez seguida de perda implicou em uma devastação emocional que podia continuar por um período extenso após a perda e ter um longo alcance na vida de uma mulher. Gestações mal sucedidas podem ter um impacto negativo, fazendo-se presentes quadros de ansiedade e um sentimento aumentado de vulnerabilidade. O mesmo é reafirmado por um estudo realizado por Bowles et al. (2006), nos Estados Unidos, o qual indica que muitas mulheres, após aborto espontâneo, podem apresentar desordem de estresse agudo, bem como estresse pós-traumático. Os autores afirmam ainda que as mulheres que desenvolveram desordem de estresse agudo eram significativamente mais propensas a apresentar desordem de estresse pós-traumático subsequente.

Nesse sentido, Brisch, Munz, Kachelle, Terinde e Kreienberg (2005) e colaboradores realizaram um estudo longitudinal e prospectivo na Alemanha, com o objetivo de avaliar o impacto das experiências anteriores como o nascimento de uma criança natimorta, aborto espontâneo ou parto prematuro sobre a ansiedade das mulheres grávidas, em vários subgrupos com alto risco para anormalidade fetal, em comparação com um grupo controle sem risco, de mulheres com gestações não complicadas. Entre os resultados encontrados pode-se destacar que todas as mulheres com gestação de alto risco apresentaram elevados níveis de ansiedade no momento imediato que precedeu o exame de ultrassonografia. Porém, 
os pesquisadores constataram um declínio significativo da ansiedade no decorrer das 10-12 semanas seguintes. Os níveis de ansiedade também diminuíram logo após o exame de ultrassom. Por outro lado, o nível de ansiedade não aumentou no grupo de mulheres com gestações não complicadas (grupo controle). No entanto, o resultado que chama mais a atenção, por interessar especificamente ao presente trabalho, consiste nos níveis elevados ou persistentemente altos de ansiedade ao longo do tempo de mulheres grávidas que tinham experienciado aborto espontâneo ou o nascimento de um bebê natimorto. Esses achados incluem também as mulheres do grupo controle que tinham vivenciado previamente esses eventos e, do mesmo modo, apresentaram níveis crescentes de ansiedade em detrimento à confirmação médica de que o desenvolvimento da gravidez atual era sem complicações. Assim, o aumento não usual dos níveis de ansiedade pareceram ser influenciados pela experiência prévia de complicações e perdas gestacionais.

Em estudo realizado no Japão, Nakano, Oshima, Sugiura-Ogasawara, Aoki, Kitamura e Furukawa (2004), chamam a atenção para a existência de alguns preditores psicossociais de êxito gestacional após vivência de abortos espontâneos recorrentes. Por meio de um estudo prospectivo baseado em duas ondas de entrevistas diretas e questionários autorrelatados com mulheres com história de aborto espontâneo recorrente, eles conseguiram identificar alguns desses preditores. Assim, a satisfação com o apoio social percebido, a atribuição estável de causas ao aborto anterior e a ausência de alguns sintomas psicológicos (especialmente a depressão) determinaram o resultado da gestação futura. Destaca-se que o humor depressivo, embora não severo o suficiente para satisfazer o critério diagnóstico para depressão maior, aumenta significativamente a probabilidade do aborto se repetir em uma nova gravidez. Já a importância da identificação das causas do aborto espontâneo também foi apontada por outras pesquisas, como a de Nikcevic, Tunkel, Kuczmierczyk e Nicolaides (1999), que consistiu em um estudo longitudinal prospectivo realizado na Inglaterra, com mulheres que realizaram uma ultrassonografia da $10^{\mathrm{a}}$ a $14^{\mathrm{a}}$ semana de gestação e receberam o diagnóstico médico 
de morte fetal ou gravidez anembrionária. Os pesquisadores, ao compararem as condições psicológicas das mulheres que tinham tido as causas dos diagnósticos identificadas e daquelas que não as tinham, atribuíram a essa identificação uma redução nos sentimentos de culpa e autorresponsabilização pelo ocorrido.

Resultados semelhantes foram encontrados em um estudo qualitativo realizado na Indonésia por Andajani-Suthahjo e Manderson (2004) com mulheres cujos bebês morreram nas primeiras semanas de vida ou nas quais houve diagnóstico de óbito fetal na gestação. De acordo com os resultados desse estudo, a falta de informações adequadas oferecidas pelos profissionais de saúde implicou na construção de fantasias a respeito da causa da perda e no sentimento de culpa. Fez-se presente também a crença de que a perda era consequência de algum ato interpretado como "mau" e cometido por elas no passado.

O aborto espontâneo, assim, compreende um evento em geral não antecipado e fisicamente traumático, que pode representar, para muitas mulheres, a ruptura abrupta dos planos reprodutivos. Ele pode despertar dúvidas sobre a competência reprodutiva, provocar uma perda na autoestima e desencadear sintomas psiquiátricos, tais como sintomas depressivos. Nesse sentido, Neugehauer et al. (1992) realizaram um estudo nos Estados Unidos a fim de testar se e sob que condições o aborto espontâneo aumenta os sintomas depressivos nas semanas iniciais após a perda. Os resultados evidenciam que as mulheres sem filhos que sofriam aborto espontâneo mostraram-se especialmente vulneráveis para sintomas depressivos. Ao contrário, a presença de vários filhos configurava-se como um elemento protetor. A presença de filhos vivos, conforme afirmam os pesquisadores, pode funcionar como um suporte psicológico indireto, por representar a evidência de sucesso reprodutivo no passado. A perda de uma gravidez desejada também foi associada com uma elevação dos níveis depressivos. Além disso, se a perda ocorreu após um tempo maior de gestação, as mulheres, aparentemente, experienciaram um aumento nos sintomas depressivos quando comparadas com mulheres que abortaram no início da gestação. De acordo com os pesquisadores, 
este resultado apresenta consistência com a noção de apego (vínculo afetivo) materno para com a criança que ainda não nasceu, na medida em que as teorias do apego defendem a ideia de que esse vínculo progride à medida que a gravidez avança e que o impacto da perda corresponde à força desse vínculo.

Contraditoriamente a esse resultado, Thomas (1995), em discussão acerca dos efeitos das perdas gestacionais involuntárias sobre as famílias na Inglaterra, afirma que a experiência emocional de uma mulher após uma perda gestacional não se encontra diretamente relacionada à experiência física, isto é, ao tempo de gestação. Para esse autor, um dos principais determinantes para a experiência emocional consiste no significado atribuído pela mulher à perda gestacional. E assim, se em estágios iniciais da gravidez a mulher considera o feto como o seu bebê, ela será emocionalmente afetada quando ocorrer o aborto espontâneo.

Swanson (2000) traz uma contribuição interessante nesse sentido, a partir de um estudo realizado nos Estados Unidos e que visava desenvolver e testar uma teoria baseada no modelo de Lazarus sobre emoções e adaptação que tornaria possível predizer a intensidade dos sintomas depressivos após quatro meses e um ano da vivência de um aborto espontâneo. Os achados do estudo evidenciam que as mulheres com maior risco para sintomas depressivos mais intensos após aborto espontâneo são aquelas que atribuem elevada significação pessoal para o aborto espontâneo, não dispõem de suporte social, têm força emocional (percepção do self como emocionalmente forte/recursos emocionais) mais baixa, usam estratégia de coping passivo, têm renda mais baixa e não engravidam ou dão à luz no período de um ano após a perda.

Com relação à significação do aborto espontâneo, o estudo encontrou uma associação positiva entre o número de abortos espontâneos prévios e a importância atribuída a este evento. Na direção oposta, quanto mais filhos as mulheres tinham, menor o significado pessoal atribuído. Significação pessoal mais alta estava associada com depressão aumentada após quatro meses e um ano após a perda. Esses resultados encontraram-se também associados com um aumento de coping passivo e ativo 
quatro meses após o aborto espontâneo e com um aumento do coping passivo após um ano. O pesquisador ressalta que esses achados após quatro meses do evento da perda sugerem que as mulheres engajaram-se em uma variedade de estratégias para lidar com a dor emocional. No entanto, o coping passivo - como se manter sozinha e culpar-se pelo ocorrido como modos de lidar com essa dor emocional - foi fortemente associado com sintomas depressivos após quatro meses e um ano do aborto espontâneo, consistindo em estratégias utilizadas pelas mulheres em que o suporte social encontra-se ausente. No entanto, segundo afirma o pesquisador, nem todas as razões das mulheres para experienciar os sintomas depressivos estavam relacionadas a seus abortos espontâneos. Isto pode significar que elas poderiam estar lidando, simultaneamente, com outros eventos de vida significativos que as levariam a vivenciar sentimentos de tristeza. Porém, uma explicação alternativa corresponde ao fato de que algumas mulheres não seriam conscientemente capazes de reconhecer para si mesmas que os abortos espontâneos tinham e seguiam tendo uma significação pessoal para ela. Isto possivelmente estaria relacionado a discursos socioculturais acerca das atitudes sociais aceitáveis que ignoram o aborto espontâneo ou a um conjunto de expectativas de que as mulheres deveriam superá-lo.

Com relação às atitudes sociais de não reconhecimento do aborto espontâneo como uma perda, Renner, Verdekal, Brier e Fallucca (2000), realizaram um estudo nos Estados Unidos com o objetivo de determinar se o aborto espontâneo é uma perda não reconhecida e avaliar o significado desse evento para as outras pessoas. De acordo com os resultados encontrados, o aborto espontâneo não compreende uma perda não reconhecida; no entanto, consiste em um evento no qual, no âmbito cultural, consegue-se apenas identificar o seu "significado base" (grounded meaning), isto é, atributos específicos, elementos e atividades que cercam o evento, mas pouco "significado avaliativo" (valuation meaning) - relacionado à importância associada com o "significado base". Conforme os pesquisadores, consiste em uma tarefa difícil para outras pessoas construírem um "significado avaliativo" para este tipo de perda, prova- 
velmente porque, em geral, essa perda não é aparente e muitas pessoas nem mesmo sabiam que a mulher estava grávida. Deste modo, sem o "significado avaliativo", as outras pessoas dispõem de recursos limitados para julgar o que dizer para uma mulher e, portanto, oferecem apenas um suporte mínimo durante este evento. Assim sendo, os pesquisadores concluem que o aborto espontâneo configura-se como uma ocorrência que possui um significado concreto para as outras pessoas, mas pouco significado emocional. As razões para esta falta de significado emocional incluem o fato de que o aborto espontâneo consiste em um evento que é tratado no âmbito cultural em silêncio, além de possuir escassos marcadores físicos que permitam a observação de que uma perda ocorreu.

Hsu, Tseng, Banks e Kuo (2004) realizaram um estudo em Taiwan com o objetivo de explorar os significados atribuídos ao óbito fetal por mulheres inseridas naquele contexto cultural. Vale ressaltar que, no contexto cultural estudado, a morte é vivenciada como um tabu e o bebê nascido morto não é reconhecido como um bebê real. Dentre os significados encontrados, destaca-se a perda de controle; a quebra de sonhos; sentimentos de incompletude; culpa; derrota pessoal; sentimento de menos-valia como mulher e em relação ao seu papel na sociedade. A dificuldade de realizar rituais de morte e expressar seus sentimentos - não autorizados culturalmente - afetaria as mulheres na elaboração adequada do luto pela morte do bebê.

Por sua vez, Callister (2006) também aponta para a profunda influência da cultura sobre as respostas - especialmente das próprias mulheres - a perda perinatal como o aborto espontâneo, a gravidez ectópica, o natimorto e a morte neonatal. Conforme este autor, em culturas onde, por exemplo, é atribuída uma importância simbólica à concepção, à gravidez e à infância, sendo altamente valioso ter filhos, a perda perinatal pode se configurar como um evento muito significativo e doloroso para uma mulher e/ou casal.

De acordo com Reagan (2003), as reações das mulheres à vivência de um aborto espontâneo não é nem puramente pessoal, nem universal. Os significados do aborto espontâneo, bem como os de maternidade, 
são cultural, social e historicamente produzidos. Enfatiza, assim, a importância do contexto para a determinação destes significados. Segundo este autor, a representação normativa do aborto espontâneo mudou drasticamente ao longo do século XX. Tomando como referência a América do Norte, argumenta que, no começo do século, o aborto espontâneo era representado como uma causa de dano físico para as mulheres. Na metade do século, era representado como boa sorte para aquelas que não queriam estar grávidas e vivenciavam a gravidez com aflição. Já no fim do século, o aborto espontâneo era representado como uma fonte de devastação emocional, uma tragédia pessoal, um sofrimento eminentemente feminino. Esta mudança ideológica que se efetivou durante a década de 1980 sofreu a influência de muitos fatores, como a de um novo movimento social surgido na Europa e nos Estados Unidos que imprimiu ao aborto espontâneo novos significados, como a equivalência deste evento à perda de uma criança, exigindo-se a vivência do sofrimento materno, assim como do luto pela perda.

Seguindo nessa mesma direção, Jutel (2006), baseado no contexto sociocultural da Nova Zelândia, chama a atenção para a variedade de termos, utilizados por diferentes comunidades para descrever uma gravidez que não resulta no nascimento de uma criança com vida. Entre esses termos destacam-se o "aborto espontâneo" e o "natimorto". De acordo com esse autor, esses termos são mais do que meras palavras, na medida em que carregam consigo uma gama de significados e consequências sociais. Ou seja, são parte de um contexto cultural e político mais amplo, expressam valores sociais e afetam a prática social.

O conteúdo cultural dos termos "aborto espontâneo" e "natimorto", assim, apresentam desafios quando analisados em profundidade. Afinal, o natimorto é distinguido do aborto espontâneo pela viabilidade potencial do feto, isto é, refere-se ao parto de um bebê que teria sido viável no momento em que ele deixou o útero materno, mas que nasceu sem vida, ao contrário do aborto espontâneo. No entanto, o que constitui viabilidade é fundamentado no estado de conhecimento da comunidade médica, sua habilidade e recursos tecnológicos para manter vivo um bebê nascido 
antes do tempo. Desta forma, nomear um evento, como a morte fetal, reflete o estado do conhecimento naquele período histórico que é fortemente influenciado pelos valores e interesses da sociedade. $\mathrm{O}$ autor problematiza, então, por que alguns bebês não viáveis podem ser considerados natimortos enquanto outros não. Na prática, as consequências dessas contradições são evidentes: os familiares de bebês natimortos, até mesmo aqueles fora dos limites atuais de viabilidade, são em geral providos com rituais de reconhecimento da concepção e do pesar, tais como certidão de nascimento e morte, e enterro, enquanto aquelas famílias que vivenciaram um aborto espontâneo não o são - apesar de, em muitos casos, os sentimentos de perda serem igualmente profundos.

A maneira pela qual a morte fetal será recebida pela mulher, por seu parceiro, familiares, sistemas de suporte e profissionais de saúde depende de circunstâncias psicológicas, sociais e individuais complexas. Assim, enquanto um grupo poderia experienciar a morte gestacional como uma perda, outro poderia percebê-la como um alívio - e, de fato, poderia voluntariamente provocá-la. Para o autor, são as posições subjetivas disponíveis para as mulheres que experienciaram a morte gestacional que são problemáticas. Mas, ainda assim, nem a mulher, nem qualquer outro indivíduo, podem mudar as palavras, os estatutos, as leis implicadas nessas posições inoportunas. Deste modo, o autor recomenda que a centralidade da mulher na gravidez enquanto protagonista seja restaurada. Afinal, quando se usa o termo "aborto espontâneo recorrente sem explicação", por exemplo, situa-se o fim da gravidez no modelo centrado nos aspectos médicos, mas perde-se de vista o significado do evento para a mulher. Trazendo a discussão de volta para a mulher, é permitido a ela reconhecer a perda de um bebê, se este é o modo como ela interpreta a experiência. O autor conclui, então, que a experiência do evento deve ser localizada não na história médica, mas na experiência vivida pela parturiente.

No contexto brasileiro, as crenças sobre gestação, parto e maternidade em gestantes com histórico de abortamento de repetição foram investigadas por Espindola, Benute, Carvalho, Pinto, Lúcia e Zugaib (2006), em São Paulo/SP. Entre os achados, os autores destacam a influência da 
cultura e dos valores sociais enquanto fatores importantes às questões referentes à gestação e a maternidade. Para as mulheres entrevistadas, gerar um filho é uma tentativa de dar novo sentido à vida, sendo uma realização que vai além da esfera pessoal, pois reflete os aspectos sociais e culturais do que se espera de uma mulher. A reprodução é vista como uma norma social, em que se espera das mulheres que desejem e gerem filhos, sendo a maternidade reforçada culturalmente como algo bom e necessário, colocando-as, conforme os autores, em uma posição extremamente vulnerável ante a possibilidade de gerá-los.

Deste modo, formar e romper vínculos com o bebê em gestação e as subsequentes reações emocionais da mulher/casal interagem com os diferentes contextos que permitem a sua expressão. Na seção a seguir serão abordados aspectos específicos sobre essas reações emocionais - na situação em que a interrupção involuntária da gestação é experienciada enquanto perda. Ou seja, serão abordados os processos envolvidos no trabalho de luto.

\section{A perda gestacional e suas reações emocionais: o processo de luto}

A elaboração do luto em decorrência à perda de um bebê é um tema que vem sendo explorado pela literatura. (Duarte \& Turato, 2009)

O luto, de acordo com Parkes (1998) compreende uma reação à perda de uma pessoa significativa. É um processo que envolve uma sucessão de quadros clínicos que se mesclam e se substituem. Apesar das diferenças que pode haver de uma pessoa para outra, o luto apresenta um padrão comum o que, conforme este autor, permite considerá-lo como um processo psicológico distinto. E assim, a primeira fase do luto, o entorpecimento, dará lugar à saudade ou à procura pela pessoa perdida, que posteriormente será substituída pela fase de desorganização e desespero que, por fim, dará lugar à fase de recuperação. (Bowlby, 2004) 
Outros autores também descrevem este padrão distinto do processo de luto. Para Worden (1998), o processo de luto é composto por quatro tarefas básicas que devem ser realizadas para que seja restabelecido o equilíbrio e completado o processo de luto. Tarefas não concluídas, de acordo com este autor, podem prejudicar o crescimento e o desenvolvimento futuros. Desta maneira, a primeira tarefa consiste em aceitar a realidade da perda, reconhecendo que esta ocorreu e que é definitiva; a segunda tarefa compreende o reconhecimento e a elaboração da dor da perda; a terceira tarefa, por sua vez, implica no esforço do enlutado em se ajustar ao ambiente onde está faltando a pessoa que morreu; e, por fim, a quarta tarefa exige do enlutado reposicionar, no âmbito da sua estrutura psicológica, a pessoa que morreu e seguir em frente com a sua vida. O luto termina quando estas tarefas são completadas.

Franco (2010a), por sua vez, descreve o luto dando ênfase a uma compreensão mais dinâmica e próxima da vivência particular, isto é, como um processo de construção de significados que permite revisões na identidade, relações sociais e sistema de crenças. Para essa autora, formar e romper vínculos faz parte da identidade humana. (Franco, 2010b)

No presente estudo, o entendimento do trabalho de luto aproxima-se dessa última proposição, sendo caracterizado como um processo afetivo-semiótico de reparação desencadeado após a ocorrência de uma ruptura e perda significativa na trajetória de vida, como é o caso de perdas gestacionais involuntárias. Entretanto, o nosso interesse incide sobre a análise dos microprocessos de reparação da ruptura que ocorrem no âmbito do self, em articulação com as interações sociais e com os aspectos socioculturais do contexto - ao longo do tempo irreversível - e a partir da perspectiva teórica do construtivismo semiótico cultural em psicologia. (Simão, 2007) Alguns dos capítulos seguintes abordarão essa análise microgenética de casos singulares. Além disso, o capítulo 9 aprofundará teoricamente o conceito de estratégias semióticas de reparação dinâmica do self - um conceito que oferece generalidade para o específico das perdas gestacionais. 
As perdas gestacionais, de acordo com Walsh e McGoldrick (1998), compreendem, muitas vezes, perdas ocultas, na medida em que são frequentemente desconhecidas das outras pessoas ou não reconhecidas, consideradas como não eventos. A preocupação inicial da rede social é com a saúde da mulher; somente aos poucos se começa a perceber, de modo mais amplo, o que foi perdido. Além disso, as mulheres parecem sentir mais profundamente a perda do que seus parceiros, vivenciando, ao mesmo tempo, uma série de preocupações. Uma das principais preocupações relaciona-se à sua capacidade de ter um filho em uma futura gravidez, podendo também se fazer presente o medo do impacto da perda sobre o relacionamento afetivo com o parceiro. (Worden, 1998) A culpa consiste em um sentimento muito comum, que pode levar à censura ou à autocensura, sendo a perda interpretada como resultado da deficiência do seu próprio corpo ou de ações danosas empreendidas. (Walsh \& McGoldrick, 1998) Os parceiros também podem ser alvo de recriminações por parte da mulher, devido à percepção de que eles não sentem o mesmo que elas. (Worden, 1998) Além do sentimento de culpa, a vergonha também pode se fazer presente, relacionada à incapacidade de dar à luz a um bebê sadio. (Bowlby, 2004)

Conforme visto acima, a perda gestacional enquanto objeto de interesse da pesquisa e teoria em psicologia já aparecia nos trabalhos de John Bowlby realizados no início da década de 1960, alicerçados em sua teoria do apego. De acordo com Bowlby (2004), apesar de o laço afetivo entre pais e filho ser ainda muito recente, os padrões gerais de reação à perda são muito semelhantes a outros tipos de perdas, como nos casos da morte de um cônjuge. Assim, pode-se fazer presente o torpor, seguido de aflição somática, anseio, raiva e subsequente irritabilidade e depressão. Outra reação à perda compreende a tentativa dos pais de substituir um filho perdido tendo outro. Conforme Bowlby (2004), essa reação revela-se perigosa, pois pode comprometer o processo de luto, além de poder levar os pais a perceber o novo filho como o retorno daquele que morreu - resultando em uma relação distorcida e patológica entre pais e filho. $\mathrm{O}$ autor ainda recomenda que os pais esperem um 
ano ou mais antes de tentar uma nova gravidez. O objetivo deste período de tempo consiste em possibilitar uma reorganização da imagem da criança perdida, conservando-a como uma lembrança viva, distinta de qualquer outro filho. Essa recomendação parece ainda pertinente nos dias atuais, na medida em que o processo psíquico de elaboração de uma perda exige tempo - ainda que não seja possível determinar quanto tempo seja necessário para a elaboração do luto.

Para Worden (1998), na medida em que perdas gestacionais como o aborto espontâneo e o natimorto envolvem a perda de uma pessoa significativa, é importante que os pais realizem o trabalho de luto. No luto por óbito fetal, são determinantes os fatores relacionados ao diagnóstico e tratamento, motivações para a gestação e fatores relativos ao seu planejamento. (Silva \& Nardi, 2011) No entanto, um dos obstáculos comum ao início desse processo consiste na dificuldade de falar sobre a perda, visto que a rede social frequentemente ou desconhecia a gravidez ou demonstra desconforto sobre esta experiência - o que inclui também os profissionais de saúde. (Worden, 1998) As mulheres nessas situações, de acordo com Doka (1989, citado por Parkes, 1998), vivenciam um "luto não autorizado", na medida em que a perda experienciada não pode ser abertamente apresentada, socialmente validada ou publicamente lamentada. E na medida em que esses aspectos fazem-se presentes, alguns problemas podem surgir na expressão do luto, como a sua intensificação em consequência do fato de ter sido ignorado ou reprimido. (Parkes, 1998)

O processo de luto vivenciado com o abortamento espontâneo pode ser entendido, conforme Benute et al. (2009), a partir de dois fatores preponderantes: a perda do filho real desejado e imaginado ou do filho potencial desencadeado a partir do momento em que uma mulher sabe que está grávida; e o desvio do padrão de comportamento esperado socialmente, na medida em que a maternidade ainda é reconhecida como uma condição inerente à mulher. A "mulher é fruto das exigências e das transformações de sua época, mas carrega consigo uma inscrição de maternidade". (Benute et al., 2009, p. 326) 
Volkmer (2009), ao analisar o processo de luto de mulheres com história de perdas gestacionais recorrentes, observou que o padrão de reação emocional mais comum após a vivência das perdas consistiu na intensificação do luto ao longo do tempo. Após as primeiras perdas gestacionais, a vivência do luto ocorreu de modo parcial ou incompleto. Alguns indícios foram encontrados nesse sentido: sentimentos de pesar e de tristeza apenas em um momento imediato à perda, mas dissipados logo que retornavam às suas casas; ao fato de se desfazerem precipitadamente e sem critérios dos pertences do bebê (evitar lembranças); de não participarem dos rituais fúnebres (evitar o reconhecimento da perda e, com efeito, o seu pesar); não querer falar sobre a perda nem sobre assuntos afins, e, em alguns casos, por engravidarem novamente logo após a perda (substituição do bebê perdido). Essas condutas parecem estar relacionadas a uma tentativa de suprimir o sofrimento emocional que a perda gestacional implicaria e de não querer assumir um luto socialmente não legitimado. Porém, com a repetição das perdas, o luto antes não vivenciado parece emergir de modo mais intenso na vida dessas mulheres, a ponto de, em alguns casos, haver o desencadear de sintomas psiquiátricos, como síndromes depressivas, transtornos de ansiedade e síndromes fóbicas.

No entanto, a intensificação das reações às perdas gestacionais também esteve associada à mudança no apoio oferecido pela rede social, em especial pelas famílias, ao longo da trajetória reprodutiva. Isto porque, para os membros da família, a repetição das perdas e do sofrimento emocional relacionado parece penetrar na esfera do insuportável, esboçando-se uma atitude de afastamento e isolamento em relação ao casal. Assim, a experiência emocional dessas mulheres aparece, com o passar do tempo, cada vez mais marcada pela culpa, medo e ansiedade. (Volkmer, 2009) Os profissionais de saúde, por sua vez, também não se apresentaram como fontes de apoio emocional, e em algumas situações foram, pelo contrário, responsáveis pela ampliação do sofrimento e do desamparo. É do que se trata na seção a seguir. 


\section{Os profissionais de saúde no atendimento dos pais após experiência de perdas gestacionais}

O comportamento dos profissionais de saúde diante uma perda gestacional envolve, desta forma, um aspecto importante no que tange ao favorecimento do trabalho de luto dos pais. De acordo com Estok e Lehman (1983), em um estudo qualitativo realizado nos Estados Unidos, após a morte de um feto ou de um bebê recém-nascido, alguns profissionais de saúde, como médicos e enfermeiros, comportam-se de modo inadequado, segundo a perspectiva dos pais enlutados. Isto porque têm dificuldade de lidar com a morte perinatal. Assim, alguns evitam a morte ou simplesmente dizem que "essas coisas acontecem"; são hostis; fazem uso de pensamento mágico fazendo referência ao fato de que os pais poderão ter outros filhos, ou que têm sorte de já ter filhos - minimizando assim o evento da perda; ou ainda submetem a mulher à sedação, isolando-a do contato com outras pessoas sob a alegação de protegê-la.

Outro estudo qualitativo, com enfoque fenomenológico, realizado na Espanha por Montero, Sánchez, Montoro, Crespo, Jaén, e Tirado (2011) também investigou a experiência de profissionais de saúde (enfermeiros, parteiras, auxiliares de enfermagem e obstetras) de um hospital público em situações de morte e luto perinatal. Os resultados do estudo revelam que a assistência prestada enfatizou os cuidados físicos, mas negligenciou os aspectos emocionais dos casais que experienciaram a perda gestacional. Deste modo, em muitas ocasiões a atuação foi caracterizada como distante, havendo a negação da gravidade da perda, principalmente em gestações precoces. De modo geral, evidenciou-se a falta de estratégias, de destreza e de recursos dos profissionais para enfrentar essas situações e dar respostas adequadas às demandas dos casais. O momento de comunicar a notícia da perda consistiu em um evento crítico para os médicos, gerando ansiedade. Assim, o evento de perda perinatal despertou nos profissionais de saúde sentimentos tais como pena, ansiedade, insegurança, ressentimento, culpa, frustração, raiva, sensação de fracasso e impotência - pois não sabem como enfrentar e manejar essas situações. 
Os pesquisadores acima citados alertam para a necessidade de uma formação específica dos profissionais sobre o pesar perinatal, habilidades de comunicação e técnicas de relacionamento de ajuda. Para eles, torna-se fundamental promover programas de treinamento voltado para os profissionais de saúde, para que eles possam adquirir conhecimentos, aptidões e habilidades em pesar perinatal e desenvolver uma diretriz de prática clínica para o cuidado da perda perinatal.

Com relação à assistência ao parto de um feto morto, o estudo realizado por Gold, Dalton e Shwenk (2007), nos Estados Unidos, revelou que quando a mulher e/ou o casal tem a opção de decidir sobre a indução do parto, o controle da dor, a posição no parto isso contribui para o desenvolvimento normal do trabalho de luto.

Algumas recomendações são tecidas na literatura, destinadas aos profissionais de saúde, a fim de que eles possam facilitar o processo de luto dos pais que perderam um bebê. Entre as orientações, pode-se destacar a necessidade dos profissionais de informar aos pais imediatamente sobre a condição do bebê e fornecer informações sobre o ocorrido baseadas em fatos, quando disponíveis; expressar sentimentos sobre a perda parental com palavras que possam consolar os pais, assim como tocá-los afetuosamente e apropriadamente, na medida em que as palavras nem sempre são necessárias ou oportunas; encorajar os pais a chorar a perda abertamente; encorajar os pais para que vejam e segurem o bebê (após a descrição da sua aparência); e, por fim, reconhecer que os pais tiveram uma perda real, uma morte, evitando agir como se a morte não tivesse ocorrido. (Estok \& Lehman, 1983; Worden, 1998) Ajudar as famílias a tornar real essa perda implica em estimulá-las a compartilhar decisões sobre a disposição do corpo, sobre a escolha do nome do bebê e a realizar e participar de rituais como funeral. Objetos como fotografias do bebê, certidão de nascimento, impressões do pé, mecha de cabelo entre outros, podem também ajudar a tornar a perda real. (Gold, Dalton, \& Shwenk, 2007; Worden, 1998)

De modo geral, Parkes (1998) orienta que os profissionais de saúde reconheçam o luto como um processo doloroso pelo qual a família 
precisa passar, cientes de que os sintomas precisam ser vistos em contexto. Além disso, ao mostrarem interesse em aceitar as necessidades dos enlutados, podem ajudá-los de modo muito mais efetivo do que, por exemplo, limitar-se a prescrever medicamentos com o objetivo de aliviar o estresse do luto.

\section{Persistência na vida: a experiência de ruptura-transição desenvolvimental na perspectiva da psicologia construtivista semiótico-cultural}

O estudo aqui apresentado alicerça-se em duas suposições teóricas centrais sobre o desenvolvimento: a irreversibilidade do tempo e a natureza semiótica e dialógica das experiências humanas. Ambas as suposições têm sido sistematicamente exploradas por duas importantes tradições teóricas: a ciência desenvolvimental e a psicologia sociocultural. (Zittoun, Valsiner, Vedeler, Salgado, Gonçalves, \& Ferring, 2013)

A ciência desenvolvimental configura-se como a perspectiva geral que é orientada em direção ao estudo dos processos desenvolvimentais. Desenvolvimento é a propriedade dos sistemas abertos de sofrer transformações nas formas qualitativas, sob constante relação com o meio ambiente, e dentro do tempo irreversível.

Por sua vez, a psicologia sociocultural afirma que o desenvolvimento humano é regulado por signos. A função semiótica media tudo, desde experiências pessoais às culturais. Os seres humanos criam signos através dos quais eles organizam e dão sentido aos seus mundos subjetivos, ao longo de toda sua vida.

É sob as lentes destas perspectivas teóricas que as experiências da gravidez, da maternidade e da perda gestacional serão analisadas. Vale ressaltar que a gravidez compreende um evento no qual a ideia de tempo irreversível torna-se mais explícita, ilustrando o relacionamento dos seres humanos com o vir a ser, com o futuro. Ao saber-se grávida, ou mesmo antes disso, uma mulher antecipa, projeta para o futuro um lugar simbólico para essa nova pessoa em sua vida, imaginando características 
físicas e de personalidade do filho, bem como o tipo de relacionamento dialógico e afetivo que será estabelecido entre eles - construções mentais que vão dando forma simbólica a um futuro filho e a uma futura mãe. Deste modo, esta relação futura e potencial é antecipada.

A ocorrência de uma perda gestacional involuntária, assim, ganha uma dimensão que não se limita ao momento presente, da perda do feto em si, mas alcança a perda de um bebê imaginado, do filho antecipado no futuro. Por esta razão, a perda gestacional espontânea é entendida em termos de ruptura, uma interrupção abrupta do processo de construção identitária em curso. Descontinuidade do sentido de si. Interrupção de um processo de adaptação à uma nova condição, isto é, da identidade social de ser mãe, através do qual práticas e campos de significados pessoais e coletivos preparam os sujeitos em transformação para o porvir.

A perspectiva teórica que une as noções de desenvolvimento humano e cultura tem sido denominada por Simão (2007) como construtivismo semiótico-cultural.

\section{Psicologia Construtivista Semiótico-Cultural}

A noção de maternidade - assim como a noção de aborto, ou de uma mulher sem filhos - é carregada de valor em nosso contexto sociocultural, sendo socialmente promovida e pessoalmente internalizada. Conforme afirmam Farinati, Rigoni e Muller (2006, p. 436):

A constituição do desejo de maternidade e paternidade faz parte da cadeia simbólica constituída da própria identidade do sujeito. Nascemos emaranhados numa teia de desejos maternos e paternos [conscientes e inconscientes], carregando as marcas de estarmos vinculados a uma trama simbólica, que transcende a biologia, mas que por meio dela revela nosso pertencimento a uma família, a uma geração, a um lugar no mundo.

A maternidade e o abortamento são situações social e culturalmente reguladas, permeadas por sugestões sociais presentes em ambientes 
humanos semioticamente organizados ou estruturados a partir da combinação de signos diversos, que possuem a função de guia social. O poder de tais situações e vivências sociais e os significados hipergeneralizados que delas emergem guiam e organizam a conduta, o pensamento e os afetos humanos, demonstrando, assim, a centralidade da cultura dentro das mentes humanas. (Valsiner, 2012)

Conforme Bruner (1997a), a cultura molda a vida e as mentes humanas, dá significado à ação e situa seus estados intencionais subjacentes (crenças, desejos e significados) em um sistema interpretativo. Pode ser definida como um conjunto de ferramentas com técnicas e procedimentos que possibilitam o indivíduo entender o seu mundo e lidar com ele. A mente, conforme este teórico, é criadora de significados e, assim, ao mesmo tempo em que é constituída pela cultura, também a constitui. (Bruner, 1997b)

Valsiner (2012), por sua vez, atribui uma natureza dinâmica e processual ao funcionamento da cultura dentro dos sistemas psicológicos humanos - o que inclui tanto o domínio intrapessoal, isto é, o sentir, o pensar e o agir, bem como o domínio interpessoal, que envolve a conduta e a prática discursiva em relação às outras pessoas. A cultura pode ser entendida como um sistema de mediação semiótica - isto é, mediação que se estabelece por meio de signos -, e que compreende uma parte inerente da organização sistêmica das funções psicológicas superiores humanas. Para Valsiner, desse modo, a cultura consiste em um processo de internalização e externalização, pessoa e mundo social constituindo-se mutuamente.

As pessoas estão envolvidas em constante reconstrução de seus mundos intrapsicológicos através da permanente troca de materiais perceptivos e semióticos com o ambiente. Nesse sentido, a internalização consiste no processo construtivo de percepção e análise das experiências ou dos materiais semióticos existentes no mundo social e de sua síntese, sob uma nova forma, dentro do domínio intrapsicológico. (Valsiner, 2012) Isto é, consiste na transformação construtiva dos significados do ambiente social para o mundo subjetivo, promovendo a inovação dos 
significados pessoais. (Zittoun et al., 2013) Por sua vez, a externalização consiste no processo construtivo de análise dos materiais existentes nas culturas pessoais, ou seja, intrapsicologicamente, durante a sua transposição do domínio interno da pessoa para o domínio externo (ambiente), e a subsequente modificação do ambiente como uma forma de nova síntese desses materiais. Os resultados da externalização alimentam prospectivamente o processo de internalização em andamento, ao mesmo tempo em que o progresso da internalização em andamento promove o processo de externalização. (Valsiner, 2012)

Assim, as pessoas, de acordo com esta perspectiva, criam signos, utilizando a sua história de construção de signos, sob a orientação de outros seres humanos que, nesse empreendimento de fabricar sentidos, são coletivamente orientados por diferentes instituições sociais. O signo, conforme Vigotski (2008), consiste em um instrumento psicológico que se produz na relação e afeta e transforma os indivíduos, que passam a funcionar na esfera do simbólico. Nas palavras do autor, o signo possui a função de mediação. Constitui um meio da atividade interna, dirigido para o controle do próprio indivíduo: "o signo é orientado internamente”. (Vigotski, 2008, p. 55) E, enquanto produção humana, atua de diversos modos: "como um elemento mediador (funciona entre, remete a), operador (faz com que seja), conversor (transforma) das relações sociais em funções mentais.... Ele pode ser concebido, ainda, em seu caráter “constitutivo, flexível e reflexivo". (Smolka, 2004, p. 45)

Desta forma, esse processo dual de internalização e externalização torna cada indivíduo uma pessoa singular, embora sob as bases de uma mesma matriz cultural, na medida em que mensagens culturais, apesar de similares para diferentes indivíduos, são transformadas e reconstruídas de modo necessariamente singular. Na transmissão cultural do conhecimento, então, os indivíduos transformam ativamente as mensagens culturais, o que conduz a múltiplos cursos de reconstrução de mensagens, e torna possível a emergência da novidade.

Essa ideia apresentada por Valsiner aproxima-se da noção de internalização ou conversão conforme entendida por Vigotski (2008). Afinal, 
conforme este teórico, a partir da lei genética do desenvolvimento cultural, todas as funções psicológicas superiores do desenvolvimento humano aparecem primeiro no nível social, entre pessoas (interpsicológico) e, apenas posteriormente - por meio da internalização - no nível individual, no interior de uma pessoa (intrapsicológico). A internalização, assim, compreende a "reconstrução interna de uma operação externa [onde um] processo interpessoal é transformado num processo intrapessoal". Essa transformação em processos internos, no entanto, é resultado de um desenvolvimento prolongado e implica em mudanças nas leis que governam a atividade das funções: "elas são incorporadas em um novo sistema com suas próprias leis”. Está envolvida aqui a reconstrução da atividade psicológica tendo como base a operação com signos, traço especificamente humano: "a internalização das atividades socialmente enraizadas e historicamente desenvolvidas constitui o aspecto característico da psicologia humana". (Vigotski, 2008, p. 58)

Deste modo, a conversão, que consiste em um processo semiótico, supõe a emergência de novidade a partir de algo que, em sua essência, continua o mesmo. No entanto, não compreende um processo passivo, mas, ao contrário, pressupõe a atividade do sujeito. Assim, a significação social das relações é convertida em significação pessoal dessas relações. "Estas adquirem o sentido que lhes dá o indivíduo". (Sirgado, 2000, p. 68) Assim sendo, a função mediadora da significação permite a reversibilidade do processo: "o que é social se converte em pessoal e o que é pessoal se converte em social”. (Sirgado, 2000, p. 69) Por outro lado, as funções mentais são dinâmicas e se encontram constantemente em movimento. E, "uma vez que o indivíduo está envolvido numa ampla rede de relações diferentes, pode-se dizer que ele é uma unidade feita de múltiplas relações em que ocupa múltiplas posições de sujeito de relação". (Sirgado, 2000, p. 72) Portanto, a ideia de pessoa social de Vigotski envolve tanto a ideia de unidade quanto a de multiplicidade, o que parece aproximar-se tanto das ideias de Bakthin acerca da polifonia, quanto da noção mais atual do self dialógico - self constituído por múlti- 
plas posições e vozes e dinamicamente em movimento, de Hermans e colaboradores (1992, 1996, 2003, 2010).

Vale ressaltar ainda, a diferenciação que Vigotski (2000) estabelece entre significado e sentido. Para ele, o sentido compreende um todo complexo e dinâmico, aquilo que é vivido de forma singular, é o signo interpretado pelo sujeito histórico, dentro de seu tempo, espaço e contexto de vida pessoal e social. O significado, por sua vez, é mais estável e preciso, engloba as significações que são vividas coletivamente, o que é convencionalmente estabelecido pelo social. De acordo com Valsiner (2012), Vigotski vislumbrava a relação entre significado e sentido em termos dinâmicos - ambos são entidades que mudam, mas a sua mudança é diferente na estrutura do tempo. A mudança do significado é mais lenta e mais restrita, se comparada à do sentido.

De modo similar à diferenciação entre sentido e significado, como entendida por Vigotski, Valsiner (2012) faz referência ao que ele denomina de cultura pessoal e cultura coletiva. A cultura pessoal, segundo este autor, compreende os significados pessoais subjetivamente construídos, o sistema de sentido pessoal. Este sistema é interdependente do domínio dos processos comunicativos mediados por signos interpessoais - isto é, interdependente da cultura coletiva - mas não determinada por este. A cultura coletiva, por sua vez, compreende a multiplicidade de mensagens comunicativas mediadas por signos interpessoais, ou seja, consiste no "conjunto de produções e significados compartilhados pelo grupo, historicamente construídos e continuamente negociados nos processos interativos entre os seres humanos". (Madureira \& Branco, 2005, p. 101) Desta forma, tanto a cultura pessoal como a coletiva são constantemente coconstruídas nos contextos das interações humanas, relacionando-se de modo dialético e contínuo. O indivíduo, deste modo, é atravessado pela história e pela cultura, é parte do todo, de acordo com a lógica da separação inclusiva - ou seja, difere estruturalmente do contexto sociocultural, mas mantém com ele uma interdependência sistêmica: "a pessoa é distinta do contexto ao mesmo tempo em que é parte dele”. (Valsiner, 2012, p. 132) 
Além disso, Valsiner (2012) também define a cultura como um mecanismo de distância psicológica. Isto significa dizer que, a partir da capacidade e propensão dos seres humanos para criar e utilizar recursos semióticos, estes se tornam aptos a se distanciar em relação aos seus contextos de vida imediatos. Desta maneira, o indivíduo é, simultaneamente, um ator que está imerso em um determinado contexto e um agente reflexivo que pode se distanciar do cenário no qual está imerso. Essa reflexão, que é, ao mesmo tempo, cognitiva e afetiva, permite que o sistema psicológico considere contextos do passado, imagine contextos no futuro, assim como assuma a perspectiva de outras pessoas.

\section{A natureza dialógica do desenvolvimento humano}

A partir da noção de cultura pessoal, como descrita por Valsiner (2012), outro conceito revela-se importante: o conceito de self dialógico. De acordo com o autor, o self dialógico consiste em uma entidade teórica (self), que é organizada através de relações dialógicas entre as suas partes componentes. Compreende, assim, o diálogo intrapsicológico entre as "partes do eu" - diálogos que ocorrem no interior da cultura pessoal. "Não apenas diferentes pessoas se engajam em diálogos, mas todos nós temos nossos próprios diálogos se processando no interior das nossas culturas pessoais". (Valsiner, 2012, p. 125) Deste modo, uma pessoa funciona com base em dois processos dialógicos, que estão mutuamente interligados: o heterodiálogo (com os outros, incluindo outros imaginários) e o autodiálogo (dentro do próprio self). (Valsiner, 2012)

Segundo Fogel, Kroyer, Bellagamba e Bell (2002), o self dialógico consiste na noção do eu composto de múltiplas posições, que interagem entre si e assumem uma perspectiva única na experiência da pessoa. Para Hermans e Hermans-Jansen (2003), o self pode ser descrito como um processo desenvolvimental multivocal e dialógico, que envolve a construção e reconstrução narrativa do significado dos eventos. O self dialógico considera a pessoa como o centro da construção social - imagi- 
nativa - de possíveis posições do Eu, baseadas na experiência no mundo social. (Valsiner, 2012)

A teoria do self dialógico foi introduzida no campo da psicologia por Hermans, Kempen e Van Loon (1992). Emergiu da interface de duas tradições: o Pragmatismo Americano e o Dialogismo Russo. No que se refere à teoria do self, a inspiração foi encontrada nos trabalhos de William James (1890) e George Mead (1934). Como teoria dialógica, foi elaborada a partir das ideias sobre processos dialógicos de Bakhtin (1973). (Hermans \& Hermans-Konopka, 2010) O principal argumento construído por Bakhtin, e seguido por Hermans et al (1992) consiste na metáfora das novelas polifônicas - especialmente as de Dostoievsky que possuem como núcleo a noção de diálogo. De acordo com Hermans e Hermans-Jansen (2003), a principal característica da novela polifônica corresponde ao fato dela ser composta por um número de pontos de vista independentes e mutuamente opostos, incorporados por personagens envolvidos em relações dialógicas. Cada personagem é considerado como o autor de sua própria visão de mundo e funciona como consciência individual, com uma voz específica. A polifonia, assim, consiste nas várias vozes que são capazes de emergir, cada uma com uma visão e compromisso específico com a vida, ressaltando que, conforme afirma Bakhtin, cada voz tem sempre um envolvimento social. Deste modo, a teoria do self dialógico iniciada por Hermans et al (1992), explora as implicações da noção de uma polifonia dialógica, concebendo o self como uma multiplicidade dinâmica de selves relativamente autônomos. (Salgado \& Gonçalves, 2007)

A ideia da polifonia dialógica é articulada ainda à distinção entre o Eu ("I") e o Mim ("me") construída por William James, que defendia o argumento de diferentes selves, bem como a rivalidade e o conflito entre eles. Isso levou Hermans e colaboradores a concluir que há uma multiplicidade descentralizada de posições do Eu que funcionam como autores relativamente independentes que contam as suas histórias de acordo com o seu ponto de vista. A psicologia narrativa, por sua vez, traz contribuições relevantes ao reconhecer a importância da voz e do diálogo para 
o entendimento da mente humana. Um dos principais defensores da abordagem narrativa na psicologia é justamente Jerome Bruner (1997a, 1997b), que argumenta a favor de uma conexão entre a noção de voz e a construção de significado. Para esse autor, há uma relação entre significado e comunidade, ou seja, o significado é sempre modelado por uma comunidade particular, em virtude da participação dos indivíduos em uma cultura. Os indivíduos entram na vida das suas comunidades como participantes em um processo público mais amplo no qual significados coletivos são constantemente negociados.

A proposição fundamental, então, subjacente ao conceito do self dialógico, é a de uma multiplicidade descentralizada de posições do Eu posições essas diferentes e, até mesmo, opostas -, organizadas em um território imaginário e dotadas de uma voz que tem histórias para contar sobre as suas próprias experiências, a partir da sua própria instância - em contraste com a ideia cartesiana do self separado, individualista e centralizado. De acordo com d'Alte, Petracchi, Ferreira, Cunha e Salgado (2007), essas vozes podem ser entendidas como personagens que interagem numa história, na qual cada personagem tem uma narrativa para contar. O self, desta forma, pode ser compreendido como narrativamente estruturado por essas posições, que compõem um campo que envolve não somente a coexistência de perspectivas diferentes, mas também a construção de hierarquias, ou seja, relações de dominância e submissão entre as vozes estão sendo constantemente negociadas: "Nessa multiplicidade de posições, algumas posições podem tornar-se mais dominantes do que outras, de modo que as vozes das posições menos dominantes podem ser subjugadas". (Valsiner, 2012, p. 128) Além disso, Hermans e Hermans-Konopka (2010) fazem referência ao conceito de coalizão de posições, enfatizando que as posições não trabalham isoladas, mas cooperam e apoiam uma às outras, levando a "conglomerações" no self que podem dominar outras posições. Há também a ideia de movimento do Eu de uma posição para outra, criando campos dinâmicos nos quais autonegociações, autocontradições e autointegrações resultam em uma grande variedade de significados. (Hermans \& Hermans-Jansen, 2003) 
Porém, falar em "voz" implica considerar um corpo que emite essa voz. Deste modo, a noção de "voz" evidencia o caráter corporalizado (embodied) do self. O self está corporalizado, sempre ligado a uma posição particular no espaço e no tempo, quer fisicamente, quer mentalmente. A natureza espacial do self se traduz em termos de posição e posicionamento. (Hermans, Kempen, \& van Loon, 1992; d'Alte et al., 2007)

Vale ressaltar, ainda, que o campo das posições do Eu envolve tanto posições internas quanto posições externas, sendo que as primeiras são sentidas como partes do si mesmo (por exemplo, "Eu-mãe"), enquanto as últimas são sentidas como parte do ambiente - isto é, referem-se a pessoas e objetos relevantes para uma ou mais posições internas. Posições externas e internas recebem a sua relevância através das suas transações mútuas ao longo do tempo. De uma perspectiva teórica, todas estas posições (internas e externas) são posições do $\mathrm{Eu}$, na medida em que elas são parte do self que é intrinsecamente estendido para o ambiente.

Nesse sentido, o self dialógico é social, já que as outras pessoas ocupam posições no self multivocalizado (Hermans \& Hermans-Jansen, 2003), e estas posições do Eu podem se comunicar umas com as outras. (Fogel, Kroyer, Bellagamba, \& Bell, 2002) Vale ressaltar, porém, conforme enfatizam Salgado e Gonçalves (2007), a necessidade de se levar em conta a alteridade, isto é, ao mesmo tempo em que o outro pode ser entendido como eu (posições externas do self), também precisa ser percebido enquanto outro (alter). Conforme Cunha (2007), alteridade implica o estabelecimento de uma contínua relação de tensão e diferença entre os interlocutores, que possibilita ao ser humano a constituição e o esclarecimento da sua própria posição e existência pessoal, através da assimilação e consciência da posição do Outro. (d'Alte et al., 2007)

Salgado e Gonçalves (2007) propõem que o self dialógico precisa ser entendido enquanto uma estrutura triádica, composto pelo eu, pelo outro e pelo o que eles denominam audiência interna. Nesse sentido, o eu ocupa o centro da experiência aqui-e-agora e agência subjetiva, afetivamente envolvido no processo de endereçamento a um outro. A linguagem e a existência humana, conforme afirmam os autores, são sempre 
endereçadas a alguém. A audiência interna, potencial, por sua vez, é responsável pela mediação entre o eu e o outro. Assim, em uma relação dialógica, a troca intersubjetiva que ocorre é acompanhada também por um diálogo interno com outra audiência potencial, pessoalmente relevante e culturalmente enraizada. Em suma, o mundo fenomenal da pessoa é estruturado pelos campos dialógicos triádicos do intercâmbio entre o eu, o outro e a audiência interna. Esse campo modela e organiza a consciência do momento presente (espaço intrapessoal) e o tipo de orientação que uma pessoa pode ter em direção a objetos e outras pessoas (espaço interpessoal).

O self, então, a partir desta perspectiva de múltiplas posições e dinamicamente em movimento, nunca está concluído, mas imerso em uma experiência de vir a ser, de um constante devir. (Fogel et al., 2002) Pode, desta forma, transformar-se a partir da possibilidade de se mover de uma posição para outra, de acordo com as mudanças na situação e no tempo, a partir de diálogos reais estabelecidos com outras pessoas ou em alguma forma de diálogo interno. (Salgado \& Gonçalves, 2007) Por conseguinte, a vivência de eventos onde ocorrem perdas, como no caso do aborto espontâneo, ou a vivência da repetição dessas perdas, como no caso do aborto de repetição espontâneo, repercute em mudanças significativas no eu. (Volkmer, 2009) Ou seja, repercute nos significados e posicionamentos desta mulher que, no lugar da maternidade - após saber-se grávida - vivencia a perda; no lugar da vida, vivencia a morte. Assim sendo, o fluxo do tempo e os diálogos estabelecidos ao longo da trajetória reprodutiva constantemente impelem a pessoa para uma nova posição na qual o momento passado tem que ser resolvido em face de um futuro antecipado coconstruído. Além disso, conforme afirmam Hermans e Hermans-Jansen (2003), alguns períodos de transição no curso de vida - como a transição não normativa envolvida na vivência de uma perda gestacional -, a transação entre self e outros é mais intensa do que em outros períodos, que podem ser vistos como relativamente estáveis do ponto de vista desenvolvimental. 
Deste modo, e em última instância, a vida humana também implica em alguma forma de estabilidade. Os padrões de posicionamento e reposicionamento podem ter algum tipo de regularidade, criando um modo de organização do self em relação com os outros. Assim, as pessoas dispõem, potencialmente, de um número infinito de vozes possíveis, mas elas tendem a tornar-se organizadas em alguns padrões mais ou menos regulares de posicionamento. (Salgado \& Gonçalves, 2007) Segundo Hermans e Hermans-Jansen (2003), a linguagem social modela o que as vozes individuais podem dizer. O sistema sociocultural de um determinado grupo influencia e constringe os sistemas de significados que emergem nas relações dialógicas.

A síntese construída sobre a teoria do self dialógico valoriza dois aspectos considerados essenciais no presente trabalho: a dinâmica interna ao selfe a consideração do self no tempo. Esses foram os signos que orientaram a análise dos casos que serão apresentados nos próximos capítulos.

\section{Objetivos do estudo}

O estudo aqui apresentado visou a investigar uma realidade aparentemente contraditória, isto é, o que acontece quando uma mulher realiza a escolha pela maternidade - escolha supostamente disponível à sua constituição feminina -, mas ao invés desta vivência, o que ela experiencia são perdas gestacionais recorrentes. Neste contexto, as perdas gestacionais são entendidas enquanto marcadores de transição no curso de vida dessas mulheres. Afinal, são eventos que podem resultar em mudanças no curso do desenvolvimento, na medida em que há a interrupção da gravidez - período decisivo no crescimento emocional de uma mulher, que possibilita reestruturações, modificações e reintegrações da personalidade. (Maldonado, 2002) A vivência de um evento não esperado, não normativo, pode ser entendida como um momento de transição, resultando em uma reorganização qualitativa, tanto em nível psicológico, como comportamental. (Cowan, 1991) Além disso, pode também refletir em mudanças nos sistemas de significado dessas mulheres, como aqueles 
relacionados à maternidade, à feminilidade, bem como à percepção de si mesma. (Volkmer, 2009)

Deste modo, uma perda gestacional consiste em um evento que ameaça o sentido do selfe maximiza incerteza. A partir dessa ideia, propomos aprofundar o entendimento acerca das dinâmicas do self dialógico durante a travessia de um momento crítico (Thompson, Bell, Holland, Henderson, \& McGrellis, 2002), que leva à ruptura daquilo que era esperado acontecer e que ameaça o sentido de self.

Assim, o objetivo do estudo desenvolvido no doutorado e, aqui apresentado, consistiu em um aprofundamento teórico e empírico sobre como o self constrói continuidade através de rupturas sucessivas ao longo da trajetória reprodutiva. Implicou entender as dinâmicas do self dialógico no fluxo do tempo, com o intuito de reorganização, de rearranjos, a fim de se manter coeso - apesar das rupturas, das recorrentes descontinuidades. 